\title{
Dried apple peel powder decreases microbial expansion during storage of beef, pork and turkey, and protects against carcinogen production during heat processing of ground beef
}

\author{
G.S. Jensen ${ }^{1,3}$, V.L. Attridge ${ }^{1}$, D.V. Bratton ${ }^{2}$, R.L. Reed ${ }^{2}$ and J.F. Stevens ${ }^{2}$ \\ ${ }^{1}$ NIS Labs, 1437 Esplanade, Klamath Falls, OR 97601, USA \\ ${ }^{2}$ Oregon State University, 203 Pharmacy Building \\ 1601 SW Jefferson Ave., Corvallis, OR 97331-3507, USA
}

\begin{abstract}
KEY WORDS: apple polyphenols, bacteria, yeast, heterocyclic amine, beef, pork, turkey
\end{abstract}

Received: 21 November 2015

Revised: $\quad 9$ March 2016

Accepted: $\quad 20$ May 2016

${ }^{3}$ Corresponding author:

e-mail: gitte@nislabs.com

\begin{abstract}
Protection of the quality of foods such as ground meat, without increased use of antibiotics, is of growing importance. Environmental microbes such as bacteria and yeast are introduced into meat during butchering and processing. Due to the increased surface area of ground meat, the microbial load is higher than in cuts of meat. The presence of non-pathogenic environmental microbes contributes to meat spoilage, including formation of potentially harmful breakdown products. Addition of antibiotics is undesired in light of the increasing microbial resistance linked to their use, and the associated implications for human and veterinary health, and cost-efficient, natural methods for reducing microbial growth prior to delivery to consumers is needed. This study examined the effects of whole dried apple peel powder (DAPP) on microbial growth during cold storage of ground meat, and tested effects on carcinogen levels after grilling. Microbial growth during cold storage, mimicking shelf-life duration, in three types of ground meat (beef, pork, turkey) was tested by kneading DAPP into the ground meat, allowing 10 days cold storage, followed by testing of aerobic, coliform and yeast colony forming units. The neurotoxin norharman in beef patties after grilling was tested by LC-MS/ MS. DAPP mixed into ground meat reduced microbial growth during cold storage. DAPP applied to meat patties in a marinade prior to grilling significantly reduced norharman levels $(P<0.05)$. The results show promise for DAPP as a natural food additive to increase food quality during storage and cooking.
\end{abstract}

\section{Introduction}

Although the discovery of antibiotics in the $20^{\text {th }}$ century revolutionized the medical field, it was quickly followed by the emergence of bacterial resistance. Despite the increasing incidence of resistant bacterial pathogens, millions of tons of antibiotics have been manufactured and applied since the discovery of resistant bacterial pathogens (Davies and Davies, 2010).
Through the overuse and misuse of antibiotics in the medical, veterinary and agricultural fields, human practices have exerted a significant selection pressure on microbial populations, which has resulted in significant threats to the treatment of human and veterinary disease worldwide. While there is currently global interest in limiting the extensive use of antibiotics in food-producing animals, as they have been linked to a rise in antibiotic-resistant foodborne pathogens (McDermott et al., 2002), 
reducing their use in the agricultural sector is still the subject of debate.

In addition to the use of antibiotics at the level of agricultural production, food products may become contaminated with antibiotic-resistant bacteria during the stages of food processing. Food preservation strategies may indirectly enhance the horizontal gene transfer between bacteria through the use of multiple environmental stresses that may be increasing the selection pressure for antibiotic resistance (Walsh and Fanning, 2008). For example, studies have found that when salt stress is used in food preservation, the sublethal concentrations of salt and reduced $\mathrm{pH}$ conditions can significantly increase the antimicrobial resistance of food-related pathogens such as Staphylococcus aureus (McMahon et al., 2007; Ganjian et al., 2012).

As antibiotic resistance continues to increase in bacterial pathogens, global interest in controlling the widespread use of antibiotics in food production has increased. According to a 2011 Summary Report from the Food and Drug Administration (FDA), the antimicrobial drugs approved for use in domestic food-producing animals include aminoglycosides, cephalosporins, ionophores, lincosamides, macrolides, penicillins, sulphas and tetracyclines (Food and Drug Administration Summary Report, 2011). Although the FDA has suggested limiting the use of these antibiotics to solely medical purposes, in many cases they are used in animal feed as growthpromoting agents to enhance production efforts. In the 2012 Guidance for Industry report, the FDA concluded that the use of antibiotics to increase production efficiency was not in the interest of public health due to the rise of antibiotic resistant bacteria (US Department of Health and Human Services, 2012). The hypothesis that antibiotic-resistant bacterial infections in humans may be derived from food sources was supported by a study analysing the correlation between antibiotic resistant Escherichia coli isolates from the human blood stream with isolates from poultry, pigs and cattle. The results showed a significant correlation in ampicillin resistance between cow and human isolates as well as resistance to ampicillin, aminoglycosides, thirdgeneration cephalosporins and fluoroquinolones between human and poultry isolates, which suggests a link between human blood stream infections and food animals (Vieira et al., 2011).

The antimicrobial effects of fruit and berry extracts have been widely studied, and inclusion of such extracts in meat and other food products has potential for improving food quality during both storage and cooking. Application and wrapping of meats in edible films containing apple polyphenols have been demonstrated to increase food safety by reducing the growth of several strains of potentially pathogenic bacteria during meat storage at various temperatures (Mild et al., 2011). In addition to a direct antimicrobial effect, an extract from apple skin was shown to significantly accelerate the thermal death of coliform bacteria in ground beef during the cooking process (Juneja et al., 2009).

Extracts rich in apple polyphenols have been shown to reduce cholesterol oxidation during cold storage of ground meats (Osada et al., 2000), and to protect from the formation of carcinogens during cooking (Cheng et al., 2007; Rounds et al., 2013). In addition, red delicious apple juice was also shown to inhibit the mutational effect of carcinogens in a bioassay involving genetically engineered V79 Chinese hamster fibroblasts expressing human enzymes responsible for the activation of some carcinogens (Platt et al., 2010). This suggests that apple polyphenols not only provide antioxidant effects and help reduce the formation of carcinogens during cooking, but they also contain compounds able to lessen the effects of those carcinogens that may still be present even at reduced levels. While treatments of meats with fruit extracts may provide a robust effect, they are less cost-effective than crude fruit powders due to the high costs associated with the extract.

This study was undertaken to examine whether a crude dried apple peel powder (DAPP), previously shown to possess antioxidant and anti-inflammatory properties, in part due to high content of polyphenols (Denis et al., 2013; Jensen et al., 2014), would provide measureable antimicrobial effects. The focus was on naturally occurring microbial forms, and mimicked the microbial load expansion as it occurs either during cold storage, during transport, at a retail store, or at home. We included three types of ground meat that show preferential presence of different types of microbes (aerobic and coliform bacteria, yeast).

Adding a crude fruit powder to meat before storage may potentially alter the surface chemistry of food during grilling. One of the carcinogens formed during grilling of meat is norharman (betacarboline; 9H-pyrido[3,4-b]indole). This neurotoxin compound is currently discussed as a potential contributor to the development of neurological diseases including Parkinson's disease (Kuhn et al., 1995; Esmaeili et al., 2012). It was therefore important to also test the effects of DAPP on norharman formation during grilling, to establish whether DAPP offers a meaningful improvement to food safety as a natural food ingredient. 


\section{Material and methods}

\section{Material}

The study was conducted at NIS Labs (Klamath Falls, OR, USA) - an independent contract research laboratory specializing in natural products research.

Dried apple peel powder (DAPP), commercially available as AppleActiv ${ }^{\mathrm{TM}}$ and AppleBoost ${ }^{\mathrm{TM}}$, was obtained from Leahy Orchards Inc., Quebec (Canada). Natural (no antibiotics added) ground beef, pork and turkey were obtained off-the-shelf as fresh-frozen 1-pound ready-to-use packages from a butcher shop in Klamath Falls, Oregon (USA). Petrifilm ${ }^{\mathrm{TM}}$ for microbiology testing (aerobic, coliform and yeast) were obtained from 3M (St. Paul, MN, USA). Butterfield's buffer was obtained from Hardy Diagnostics (Olympia, WA, USA). Norharman (synonyms: norharmane, $\beta$-carboline, 9-Hpyrido[3,4-b]indole) was purchased from SigmaAldrich (St. Louis, MO, USA).

\section{Preparation of meat for cold storage}

The ground meat was obtained directly from the slaughterhouse where the meat was frozen immediately after slaughter and processing, and kept frozen until thawing for the testing. The thawed meat was kneaded for 1 min using sterile utensils to ensure even distribution of lean meat, fat and microbial forms, and divided into portions of $125 \mathrm{~g}$. One portion of each type of meat was left as is. Another portion of each type of meat was kneaded for one min with $4.8 \mathrm{~g}$ of DAPP, for a ratio of $0.038 \mathrm{~g}$ DAPP $\cdot \mathrm{g}^{-1}$ meat, or a total of $3.7 \%$ of the total weight (meat + DAPP). Each $125 \mathrm{~g}$ portion was divided into $25 \mathrm{~g}$ portions and placed in sterile $50 \mathrm{ml}$ polypropylene vials. Vials were placed in a refrigerator $\left(2-8^{\circ} \mathrm{C}\right)$ for 10 days.

\section{Microbiology testing}

After 10 days of cold storage, each portion of $25 \mathrm{~g}$ of meat was transferred into a $100 \mathrm{ml}$ container of sterile water. The container was shaken vigorously to allow microbes to disperse into the buffer. The container was allowed to sit for $5 \mathrm{~min}$ to allow solids to settle and fat to float to the top. Using a sterile bulb pipette, $10 \mathrm{ml}$ of liquid was transferred from the middle liquid layer. Serial 10-fold dilutions were made in sterile water. One $\mathrm{ml} \mathrm{sam-}$ ples from each dilution were plated in triplicate onto each type of Petrifilm. Triplicate controls were also made for sterile water alone, to account for any introduction of microbial forms during handling and plating.
Aerobic and E. coli/coliform Petrifilm were incubated for $48 \mathrm{~h}$ at $35{ }^{\circ} \mathrm{C}$, following the manufacturer's instructions. Yeast plates were incubated at room temperature $\left(20-25{ }^{\circ} \mathrm{C}\right)$ for 3 days before counting of yeast colonies, following the manufacturer's instructions. Built-in indicator dyes on each type of plate allows colony counting without further handling. Counts of colony-forming units (CFUs) per Petrifilm were performed and the average and standard error were calculated for each triplicate set of films.

\section{Preparation of DAPP-containing marinade}

A marinade was prepared by mixing $240 \mathrm{ml}$ olive oil (Carapelli extra virgin oil, Florence, Italy), $120 \mathrm{ml}$ of a commercial source of lemon juice (Sun Tree lemon juice EZ-501, Nielsen Citrus Suntree, Huntington Beach, CA, USA), and $120 \mathrm{ml}$ apple cider vinegar (Heinz North America, Pittsburgh, PA, USA). A $120 \mathrm{ml}$ sample of the marinade (sufficient for 4 meat patties) was used without adding DAPP (marinade control). DAPP was added, at various doses $(0.56,1.12$, and $2.25 \mathrm{~g}$ per meat patty), to three separate $120 \mathrm{ml}$ samples of the marinade (each sufficient for 4 meat patties). The amount of marinade applied was $30 \mathrm{ml}$ ( 1 fluid ounce) per meat patty. All samples of marinade were thoroughly mixed immediately before applying to the patties.

\section{Preparation of meat for grilling}

Thirty-two meat patties, each weighing $113 \mathrm{~g}$, were prepared as follows (Table 1). Eight 450-g portions of ground beef were made. One of the portions was kneaded with $2.25 \mathrm{~g}$ of DAPP/meat patty prior to forming the meat patties, whereas the other portions were formed without adding DAPP into the meat prior to shaping the patties. Uniform 4 ounce $(113 \mathrm{~g})$ meat patties were shaped using a press with a diameter of $9 \mathrm{~cm}(3.55$ ") and a height of $1.8 \mathrm{~cm}\left(0.7^{\prime \prime}\right)$. Four patties were left uncooked and served to verify the absence of norharman in the uncooked meat. Two sets of four patties were cooked without marinade, and served as a baseline control for norharman formation during grilling. The remaining meat patties were treated in quadruplicate with marinade either with or without DAPP. Meat patties were grilled until well done. Colour was evaluated by photographic documentation, and reviewed by three people. The odour was evaluated subjectively by the technician performing the testing. The patties were cooled and frozen prior to storage at $-25{ }^{\circ} \mathrm{C}$ and subsequently testing of norharman content. 
Table 1. Norharman levels in beef patties after grilling with dried apple peel powder (DAPP)

\begin{tabular}{|c|c|c|c|c|}
\hline \multirow{2}{*}{ Group } & \multirow{2}{*}{ No. of patties } & \multirow{2}{*}{$\begin{array}{l}\text { Norharman', } \\
\mathrm{ng} \cdot \mathrm{g}^{-1}\end{array}$} & \multicolumn{2}{|c|}{$\begin{array}{c}\text { Significance } \\
\end{array}$} \\
\hline & & & compare to $\mathrm{A}^{2}$ & compare to $\mathrm{C}^{2}$ \\
\hline Uncooked meat patties, no DAPP, no marinade & 4 & Not detected ${ }^{3}$ & & \\
\hline \multicolumn{5}{|l|}{ Cooked meat patties } \\
\hline A. no marinade, no DAPP & 8 & $7.08 \pm 2.2$ & & \\
\hline B. DAPP in meat $2.25 \mathrm{~g}^{4}$, no marinade & 4 & $8.15 \pm 3.3$ & & \\
\hline C. marinade, no DAPP & 4 & $10.33 \pm 4.8$ & & \\
\hline D. marinade with DAPP $2.25 \mathrm{~g}^{4}$ & 4 & $4.35 \pm 0.9$ & $P<0.05$ & $P<0.05$ \\
\hline E. marinade with DAPP $1.12 \mathrm{~g}^{4}$ & 4 & $4.33 \pm 0.5$ & $P<0.05$ & $P<0.05$ \\
\hline F. marinade with DAPP $0.56 \mathrm{~g}^{4}$ & 4 & $4.50 \pm 0.2$ & $P<0.05$ & $P<0.05$ \\
\hline
\end{tabular}

1 the mean \pm standard deviation is shown as ng norharman per $g$ of meat. All treatments were tested in quadruplicate, with the exception of the meat patties without marinade and without DAPP where two groups of 4 patties were averaged; ${ }^{2}$ the statistical analysis was performed by comparing patties in groups $\mathrm{D}, \mathrm{E}$, and $\mathrm{F}$ to group $\mathrm{A}$ (no marinade and no DAPP), and by comparing to group $\mathrm{C}$ (with marinade but no DAPP); ${ }^{3}$ the lower limit of quantitation of norharman was $0.5 \mathrm{ng} \cdot \mathrm{g}$ meat; ${ }^{4}$ the doses of DAPP indicated in the table refer to the dose of DAPP per meat patty

\section{Testing of norharman content}

The testing for norharman content was performed at Oregon State University (USA).

Testing of norharman content was performed by liquid chromatography-tandem mass spectrometry (LC-MS/MS) after sequential low and high $\mathrm{pH}$ extraction to reduce the fat content. Aliquots of ground meat $(4-8 \mathrm{~g})$ were homogenized in methanol $\left(20 \mathrm{ml} \cdot \mathrm{g}^{-1}\right)$ in a Waring-type blender at the highest setting for 2 min and filtered through Whatman \#1 filter paper. Duplicate $5 \mathrm{ml}$ aliquots of filtrate were taken to dryness using a stream of nitrogen at $50{ }^{\circ} \mathrm{C}$ on a Turbovap LV evaporator (Zymark Corp., Hopkinton, MA, USA), redissolved in $5 \mathrm{ml}$ ethyl acetate and extracted with $5 \mathrm{ml}$ of $0.01 \mathrm{~N} \mathrm{HCl}$. The aqueous phase was taken to $\mathrm{pH} 9$ with the addition of $60 \mathrm{ml}$ of a 1:1 dilution of ammonium hydroxide and water and then extracted with $2 \times 5 \mathrm{ml}$ ethyl acetate. The organic phase was taken to dryness (Turbovap) and redissolved in $0.5 \mathrm{ml}$ acetonitrile and centrifuged prior to analysis. Norharman was separated using a $2.1 \times 150 \mathrm{~mm} \mathrm{C8}$ Extend column (Agilent Technologies, Santa Clara, CA, USA) eluted with a linear gradient ( 5 to $100 \%$ in $6 \mathrm{~min}$ ) of solvent $\mathrm{B}(0.1 \%$ formic acid in acetonitrile) in solvent $\mathrm{A}$ (aqueous $0.1 \%$ formic acid) at $0.5 \mathrm{ml} \cdot \mathrm{min}^{-1}$ Norharman was detected using a LC-MS/MS system 4000QTrap (AB Sciex, Framingham, MA, USA) operated in the positive ion mode at a source temperature of $550^{\circ} \mathrm{C}$ with a needle voltage of $5000 \mathrm{kV}$. Norharman was quantitated using the peak areas of the ion transition of $\mathrm{m} / \mathrm{z} 169$ to 115 and the external standard calibration method. Each sample from a set of 4 patties was tested in duplicate, including duplicate extraction. Duplicates were averaged, and then the averages and standard deviations for each quadruplicate set of meat patties were calculated.

\section{Statistical analysis}

Average and standard deviation for each data set were calculated using Microsoft Excel ver. 2013 (Microsoft, Redmond, WA, USA). Statistical analysis was performed using the independent t-test. Differences were deemed significant if $P<0.05$ and highly significant if $P<0.01$.

\section{Results}

\section{Appearance of meat treated with DAPP}

The colour of ground beef, pork and turkey kneaded with $3.7 \%$ DAPP was slightly richer in colour, taking on a slightly deeper tone of reddishbrown. The ground meat did not otherwise show altered characteristics in appearance or handling. There was no appreciable difference in taste when comparing grilled meat with or without DAPP added into the ground meat, or brushed on as a marinade.

\section{Reduced microbial growth in the presence of DAPP}

The microbial load in ground beef, pork and turkey was reduced when DAPP was kneaded into the meat prior to 10 days cold storage $\left(3-5{ }^{\circ} \mathrm{C}\right)$ (Figure 1A-C). For beef, the total aerobic and coliform colony-forming units (CFU) were significantly reduced in the presence of DAPP. For pork, DAPP was associated with significant reduction in aerobic, coliform and yeast CFU after storage. For turkey, there was a significant reduction in coliform and yeast CFU in the presence of DAPP. The DAPP itself showed very low microbial content (aerobic bacteria: $200 \mathrm{CFU} \cdot \mathrm{g}^{-1} \mathrm{DAPP}$; coliform and yeast below the $100 \mathrm{CFU} \cdot \mathrm{g}^{-1}$ level of detection), indicating that DAPP did not introduce noteworthy levels 
of microbes when kneaded into the meat. Thus, the microbial contribution by DAPP was below the levels displayed in Figure 1, where the data are displayed in thousands. The CFU counts for the buffer controls showed negligible counts (one out of 3 control Petrifilm for aerobic counts had $1 \mathrm{CFU}$, and none of the coliform or yeast plates had any microbial growth), indicating that negligible amounts of microbes were introduced by handling and plating.
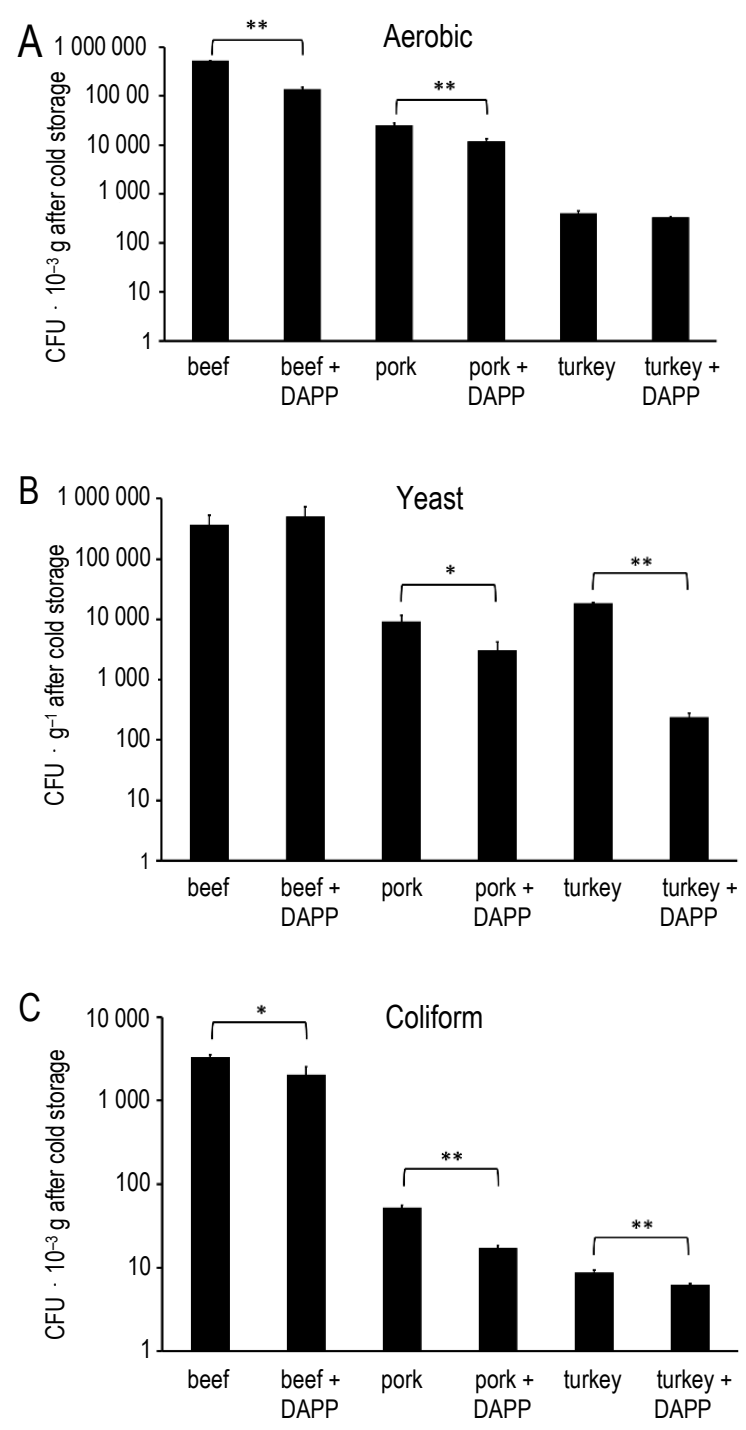

Figure 1. Microbial (A. aerobic bacteria, B. yeast, C. coliform bacteria) growth in ground beef, pork and turkey during 10 days cold storage $\left(3-5{ }^{\circ} \mathrm{C}\right)$ in the presence vs absence of dried apple peel powder (DAPP). Statistical analysis was performed by comparing each triplicate set of cultures without DAPP to the set with DAPP added, using Student's 2-tailed t-test. The levels of significance are indicated with asterisks, where $P<0.05$ is indicated with *, and $P<0.01$ is indicated with *

\section{Reduced formation of norharman during grilling of beef patties marinated with DAPP}

No significant difference was observed for norharman levels in meat patties where DAPP was mixed into the ground meat prior to grilling.
Thus, DAPP in the ground meat did not contribute to an increased level of norharman. In contrast, a significant reduction in norharman levels was seen when DAPP was applied to the surface of the meat patties prior to grilling. Meat brushed with marinade alone (without DAPP) showed a mild, insignificant increase in norharman levels compared to untreated meat patties. In contrast, meat patties where the marinade contained DAPP at different doses showed significantly lower norharman levels after grilling at all doses tested $(0.52-2.25$ g per meat patty; $P<0.05)$ (Table 1).

\section{Discussion}

To the best of our knowledge, this is the first study regarding the effects of whole dried apple peel as an ingredient to improve specific food safety parameters. Previous studies have used apple juice, which would only contain limited amounts of compounds such as triterpene acids known to be concentrated in the peel (McGhie et al., 2012; Karaman et al., 2013), and also would contain very low levels on non-aqueous compounds such as quercetin (Vasantha et al., 2011). Other studies have focused on commercialization of edible films containing apple puree. Recently, ethanol-based polyphenol isolates from apple peel were tested as a natural method to prevent or reduce fish oil oxidation (Sekhon-Loodu et al., 2013). From a health perspective, the use of the peel offers a broad spectrum of the beneficial antioxidants that are concentrated in the peel. From an economical perspective, the addition of apple peel powder to various foods during processing offers a cost-effective method for improving food safety.

The addition of DAPP to samples of ground beef, pork and turkey prior to cold storage resulted in a significant reduction in the proliferation of several types of microbial forms for all three food products. This suggests that DAPP has measurable antimicrobial activity against naturally occurring bacteria. Of special interest is the decrease in yeast CFUs in ground turkey. The robust $1.8 \mathrm{log}$ reduction in yeast CFU is within the range of antimicrobial effects seen with apple-based edible films containing botanical-derived extracts and compounds such as cinnamaldehyde and carvacrol (Ravishankar et al., 2009; Mild et al., 2011). The expansion of yeast populations in ground poultry meat during cold storage, and its contribution to poultry meat spoilage due to proteolysis and lipolysis, has been described (Ismail et al., 2000), and therefore the significant reduction in yeast CFUs when the ground turkey was kneaded with DAPP prior to cold storage is 
promising. As consumer demand for natural food products increases, there may be increased interest in natural antimicrobials for food preservation. Additionally, if stricter regulations are put into place to limit the use of antibiotics in the future, there will be a need for practical and cost-effective natural methods for controlling bacteria and improving food safety. Due to its natural antimicrobial properties, DAPP may represent a feasible solution for reducing microbial load during cold storage without the use of antibiotics, which may be critically important for improving food safety and protecting public health in the future.

The addition of DAPP to the ground meat could potentially lead to a decrease in the formation of heterocyclic amines during cooking, since the formation of heterocyclic amines during heating of organic material, and the exposure of humans to these compounds from cooked foods, toasted breads, tobacco smoking and beverages, such as coffee, is well known (Herraiz, 2004). Although there was no significant change in norharman content when DAPP was kneaded into the beef patty, we cannot rule out that lean beef with a lower fat percentage may have allowed us to detect a protective effect by DAPP. Relatively low levels (nanogram range) of norharman were generated in beef during grilling, in contrast to other foods in the microgram range. Further research is needed to determine whether DAPP may help lower the production of heterocyclic amines if applied prior to the heating process.

A reduction in the formation of norharman was observed when DAPP was applied in an oil/vinegar marinade. The $40 \%$ reduction was of a similar magnitude as the approximately $50 \%$ reduction of formation of the heterocyclic amine MelQX in heated beef patties by concentrated extracts of olive and apple, and importantly, also similar to the reported $47 \%$ inhibition of MelQX formation by crude onion powder, which may serve as a better comparison of the crude apple peel powder than highly purified plant extracts. Also, the application of DAPP in an oily marinade may be important, since liposomal solutions of another polyphenol-rich botanical product, grape seed extract, was shown to reduce the formation of heterocyclic aromatic amines (Natale et al., 2014). There was no significant difference in norharman levels in patties treated with the three different doses of DAPP. The apparent lack of a dose response may indicate that the protective effect was already saturated at the lowest dose of $0.56 \mathrm{~g}$ DAPP per meat patty. Further testing should explore the minimum effective dose in more detail, and this evaluation should also include other more prevalent carcinogenic heterocyclic amines such as aminoimidazo-quinolines, or amino-imidazo-quinoxalines (collectively called IQ-type compounds), and aminoimidazo-pyridines.

\section{Conclusions}

The protective effect of the application of a dried apple peel powder (DAPP)-containing marinade or baste to the surface of food prior to grilling may pertain to all foods, including cut meat, seafood, vegetables and baked goods. Further work is needed to examine whether, in some foods, DAPP may also reduce the levels of heterocyclic amines when mixed with the food. The kneading of DAPP into meat before storage, and its ability to reduce the formation of norharman if applied in a marinade prior to grilling, suggests that DAPP offers a natural method to improve food quality.

\section{Acknowledgements}

The study was sponsored by Michael Leahy, CEO Leahy Orchards Inc., Franklin Centre, Quebec (Canada).

\section{References}

Cheng K.-W., Wu Q., Zheng Z.P., Peng X., Simon J.E., Chen F., Wang M., 2007. Inhibitory effect of fruit extracts on the formation of heterocyclic amines. J. Agr. Food Chem. 55, 10359-10365

Davies J., Davies D., 2010. Origins and evolution of antibiotic resistance. Microbiol. Mol. Biol. Rev. 74, 417-433

Denis M.C., Furtos A., Dudonné S., Montoudis A., Garofalo C., Desjardins Y., Delvin E., Levy E., 2013. Apple peel polyphenols and their beneficial actions on oxidative stress and inflammation. PLoS ONE 8, e53725, doi:10.1371/journal.pone.0053725

Esmaeili M.H., Movahedi M., Faraji A., Haghdoost-Yazdi H., 2012. Intracerebral injection of low amounts of norharman induces moderate Parkinsonism-like behavioral symptoms in rat. Neurotoxicol. Teratol. 34, 489-494

Food and Drug Administration; Department of Health and Human Services, 2011. Summary Report on Antimicrobials Sold or Distributed for Use in Food-Producing Animals. Accessed from:http://www.fda.gov/downloads/Forlndustry/UserFees/ AnimalDrugUserFeeActADUFA/UCM338170.pdf

Ganjian H., Nikokar I., Tieshayar A., Mostafaei A., Amirmozadari N., Kiani S., 2012. Effects of salt stress on the antimicrobial drug resistance and protein profile of Staphylococcus aureus. Jundishapur J. Microbiol. 5, 328-331

Herraiz T., 2004. Relative exposure to beta-carbolines norharman and harman from foods and tobacco smoke. Food Addit. Contam. 21, 1041-1050

Ismail S.A.S., Deak T., Abd El-Rahman H.A., Yassien M.A.M., Beuchat L.R., 2000. Presence and changes in populations of yeasts on raw and processed poultry products stored at refrigeration temperature. Int. J. Food Microbiol. 62, 113-121 
Jensen G.S., Attridge V.L., Benson K.F., Beaman J.L., Carter S.G., Ager D., 2014. Consumption of dried apple peel powder increases joint function and range of motion. J. Med. Food 17 , 1204-1213

Juneja V.K., Bari M.L., Inatsu Y., Kawamoto S., Friedman M., 2009. Thermal destruction of Escherichia coli 0157:H7 in sous-vide cooked ground beef as affected by tea leaf and apple skin powders. J. Food Protect. 72, 860-865

Karaman S., Tütem E., Başkan K.S., Apak R., 2013. Comparison of antioxidant capacity and phenolic composition of peel and flesh of some apple varieties. J. Sci. Food Agric. 93, 867-875

Kuhn W., Müller T., Große H., Dierks T., Rommelspacher H., 1995. Plasma levels of the $\beta$-carbolines harman and norharman in Parkinson's disease. Acta Neurol. Scand. 92, 451-454

McDermott P.F., Zhao S., Wagner D.D., Simjee S., Walker R.D., White D.G., 2002. The food safety perspective of antibiotic resistance. Anim. Biotechnol. 13, 71-84

McGhie T.K., Hudault S., Lunken R.C.M., Christeller J.T., 2012. Apple peels, from seven cultivars, have lipase-inhibitory activity and contain numerous ursenoic acids as identified by LC-ESIQTOF-HRMS. J. Agr. Food Chem. 60, 482-491

McMahon M.A.S., Xu J., Moore J.E., Blair I.S., McDowell D.A., 2007. Environmental stress and antibiotic resistance in food-related pathogens. Appl. Environ. Microbiol. 73, 211-217

Mild R.M., Joens L.A., Friedman M., Olsen C.W., McHugh T.H., Law B., Ravishankar S., 2011. Antimicrobial edible apple films inactivate antibiotic resistant and susceptible Campylobacter jejuni strains on chicken breast. J. Food Sci. 76, M163-M168

Natale D., Gibis M., Rodriguez-Estrada M.T., Weiss J., 2014. Inhibitory effect of liposomal solutions of grape seed extract on the formation of heterocyclic aromatic amines. J. Agr. Food Chem. $62,279-287$

Osada K., Hoshina S., Nakamura S., Sugano M., 2000. Cholesterol oxidation in meat products and its regulation by supplementation of sodium nitrite and apple polyphenol before processing. J. Agr. Food Chem. 48, 3823-3829
Platt K.L., Edenharder R., Aderhold S., Muckel E., Glatt H., 2010. Fruits and vegetables protect against the genotoxicity of heterocyclic aromatic amines activated by human xenobiotic-metabolizing enzymes expressed in immortal mammalian cells. Mutat. Res. - Gen. Tox. Environ. Mutagen. 703, 90-98

Ravishankar S., Zhu L., Olsen C.W., McHugh T.H., Friedman M., 2009. Edible apple film wraps containing plant antimicrobials inactivate foodborne pathogens on meat and poultry products. J. Food Sci. 74, M440-M445

Rounds L., Havens C.M., Feinstein Y., Friedman M., Ravishankar S., 2013. Concentration-dependent inhibition of Escherichia coli 0157:H7 and heterocyclic amines in heated ground beef patties by apple and olive extracts, onion powder and clove bud oil. Meat Sci. 94, 461-467

Sekhon-Loodu S., Warnakulasuriya S.N., Rupasinghe H.P., Shahidi F., 2013. Antioxidant ability of fractionated apple peel phenolics to inhibit fish oil oxidation. Food Chem. 140, 189-196

U.S. Department of Health and Human Services, Food and Drug Administration, Center for Veterinary Medicine, 2012. Guidance for Industry: The Judicious Use of Medically Important Antimicrobial Drugs in Food-Producing Animals. Accessed from: http://www.fda.gov/downloads/AnimalVeterinary/GuidanceComplianceEnforcement/\%20GuidanceforIndustry/ UCM216936.pdf2

Vasantha Rupasinghe H.P., Kathirvel P., Huber G.M., 2011. Ultrasonication-assisted solvent extraction of quercetin glycosides from 'Idared' apple peels. Molecules 16, 9783-9791

Vieira A.R., Collignon P., Aarestrup F.M., McEwen S.A., Hendriksen R.S., Hald T., Wegener H.C., 2011. Association between antimicrobial resistance in Escherichia coli isolates from food animals and blood stream isolates from humans in Europe: an ecological study. Foodborne Pathog. Dis. 8, 1295-1301

Walsh C., Fanning S., 2008. Antimicrobial resistance in foodborne pathogens - a cause for concern? Curr. Drug Targets 9, 808-815 